\title{
Estimation of genetic and phenotypic parameters for sow productivity traits in South African Large White pigs
}

\author{
B. Dube ${ }^{1}$, Sendros D. Mulugeta ${ }^{1}$ \& K. Dzama ${ }^{2}$ \\ ${ }^{1}$ Department of Animal Science, North West University, Private Bag X2046, Mmabatho 2735, South Africa \\ ${ }^{2}$ Department of Animal Sciences, Stellenbosch University, Private Bag X1, Matieland 7602, South Africa
}

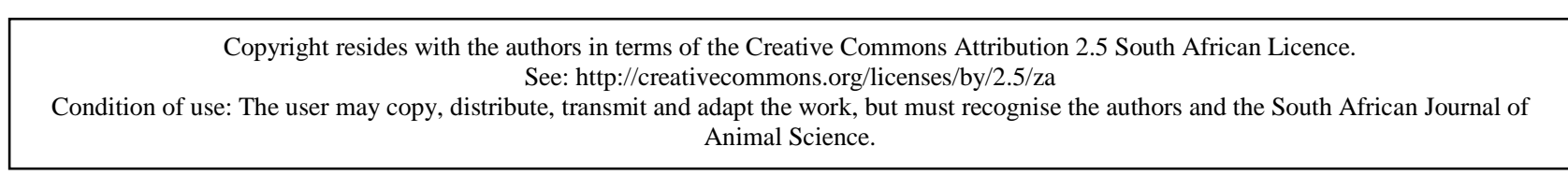

\begin{abstract}
The objective of the study was to estimate genetic and phenotypic parameters for sow productivity traits of South African Large White pigs, using data from the Integrated Registration and Genetic Information Systems. The analyses were done on 29719 records for 7983 sows from 29 herds, which farrowed between 1990 and 2008. Data were analysed as a sow trait using a repeatability animal model. The traits analysed were number of piglets born alive (NBA), litter birth weight (LBWT), 21-day litter size (D21LS) and 21-day litter weight (D21LWT). Estimates of heritability for these traits were $0.07 \pm 0.01,0.11$ $\pm 0.01,0.03 \pm 0.01$ and $0.06 \pm 0.01$, respectively. The respective repeatability estimates for the traits were $0.15 \pm 0.01,0.16 \pm 0.01,0.11 \pm 0.01$ and $0.12 \pm 0.01$. Genetic correlations among the traits ranged from 0.32 \pm 0.07 between NBA and D21LWT to $0.88 \pm 0.04$ between NBA and D21LS. The phenotypic correlations ranged from $0.35 \pm 0.01$ between NBA and D21LWT to $0.75 \pm 0.01$ between NBA and LBWT. Litter traits at birth were more heritable and repeatable than traits measured at 21 days of age. In general, all traits showed positive genetic and phenotypic trends for the period studied. The heritability of sow productivity traits was low and less repeatable, which suggests that response to selection may be slow and that the performance in the first parity may not always predict future performance. However, because of their economic importance, an attempt should always be made to keep these traits at their optimum.
\end{abstract}

Keywords: Reproductive traits, pigs, genetic progress, phenotypic performance, correlations Corresponding author: Bekezela.Dube@nwu.ac.za; Bee.Dube@gmail.com

\section{Introduction}

In pig production systems, enterprise revenue and costs depend on the weight and number of animals raised to marketing. Reproduction is the source of all market and breeding animals. Thus sow productivity contributes most to the revenue and costs of any pig enterprise. To improve the profits obtained from an enterprise, the number of live piglets born should be improved. The survival of these piglets until weaning is equally important, after which they do not depend on the sow for survival. Therefore, sow productivity has been identified as a key factor affecting the efficiency and economic viability of the pig industry (Kim, 2001). Productivity per farrowing is usually considered the basis for evaluating the genetic merit of animals in a herd (Bereskin, 1984). Improvement of sow productivity substantially reduces production costs per pig marketed (Irgang et al., 1994). The cumulative and permanent nature of genetic improvement is an important motive to consider sow productivity traits in a selection programme to improve the efficiency of pig enterprises.

To implement genetic selection for sow productivity, genetic parameters should be estimated. Estimates of genetic parameters for sow productivity traits reported in previous studies have shown that these traits are generally of low heritability (Ferraz \& Johnson, 1993; Roehe et al., 2009). Low estimates of heritability for these traits do not discourage genetic selection in the populations studied. The heritability estimates give an indication of the rate of genetic progress that can be achieved when genetic selection is 
applied. Even though heritability estimates are low, it is necessary for pigs to be selected based on genetic merit to ensure that every improvement is cumulative and permanent. This also enables the evaluation of selection programmes through the estimation of genetic trends. Comparison of genetic and phenotypic trends helps to assess whether genetic improvement is translated to superior performance, on which the remuneration for producers is based. Although several studies have been conducted on sow productivity traits (Roehe \& Kennedy, 1995; Crump et al., 1997; Hanenberg et al., 2001; Chimonyo et al., 2006), there is a lack of information on these traits in the South African pig industry. The purpose of this study is therefore to estimate genetic parameters for sow productivity traits and to evaluate genetic improvement of sow productivity in the South African Large White pigs.

\section{Materials and Methods}

The study was conducted on South African Large White sows from 29 herds across the country. Data used in the analysis were obtained from the Integrated Registration and Genetic Information System (INTERGIS) of South Africa. Pedigree information was obtained from the Large White breed society. The aim of the study was to evaluate sow productivity, and the traits were treated as traits of the dam. The original data set comprised 47578 records on 15359 sows. After removing missing farrowing dates, the data were edited by removing records that were greater or less than three standard deviations from the mean, and contemporary groups with fewer than five animals and/or fewer than two sires to ensure connectedness. Records for 21-day traits for gilts were missing. Contemporary groups were created by concatenating herd, year and season of farrowing. The seasons of farrowing that were considered were summer (October to March) and winter (April to September). The final data set comprised 21127 records on 7983 sows from 29 herds, 1189 sires and 3857 dams, which farrowed between 1990 and 2008. Parity was fitted as a fixed effect and only eight parities were considered in this study. The distribution of records across these parities is shown in Table 1.

Table 1 Distribution of sows, sires, dams, herds, contemporary groups and litter size across parities

\begin{tabular}{lcccccc}
\hline Parity & Sows & Sires & Dams & Herds & HYS & Litter size \\
\hline 1 & 7983 & 1189 & 3857 & 29 & 330 & 9.71 \\
2 & 6281 & 1122 & 3344 & 28 & 326 & 10.41 \\
3 & 4773 & 1024 & 2785 & 28 & 316 & 11.07 \\
4 & 3542 & 924 & 2193 & 26 & 294 & 11.24 \\
5 & 2549 & 797 & 1721 & 26 & 269 & 11.24 \\
6 & 1792 & 658 & 1293 & 25 & 243 & 11.10 \\
7 & 1204 & 503 & 907 & 24 & 218 & 11.00 \\
8 & 801 & 394 & 625 & 22 & 190 & 10.76 \\
\hline
\end{tabular}

HYS: herd, year and season of farrowing contemporary group.

The traits analysed were number of piglets born alive per parity (NBA), litter weight at birth (LBWT), 21-day litter size (D21LS) and 21-day litter weight (D21LWT). Number born alive is the number of live piglets born to a particular parity of a specific sow and LBWT is the total weight of live piglets of a particular sow at birth per parity. Twenty-one-day litter size is the number of piglets from a given sow that reached 21 days of age, and the total weight of these piglets is D21LWT. The summary statistics for these traits are shown in Table 2. 
Table 2 Summary statistics for sow productivity traits

\begin{tabular}{lccccc}
\hline Trait & Records & Mean & Min & Max & SD \\
\hline NBA (pigs) & 21127 & 10.46 & 4 & 16 & 2.42 \\
LBWT (kg) & 21127 & 15.24 & 6 & 28 & 3.48 \\
D21LS (pigs) & 15076 & 8.50 & 4 & 13 & 1.70 \\
D21LWT (kg) & 15076 & 47.50 & 19 & 76 & 11.07 \\
\hline
\end{tabular}

NBA: number born alive; LBWT: litter birth weight; D21LS: 21-day litter size;

D21LWT: 21-day litter weight.

General linear analysis procedures were used in SAS (2003) to select significant fixed effects to be included in the genetic model. Random effects included in the analyses were animal direct genetic and permanent environmental effects associated with each sow. Random effects included in the analyses were determined using the log-likelihood ratio tests. The difference between the two log-likelihoods was multiplied by two and compared with Chi-squared values, with degrees of freedom equal to the difference between the original and the reduced model. Table 3 shows the fixed and random effects included in the analysis of the respective traits.

Table 3 Fixed and random effects included in the model for sow productivity traits

\begin{tabular}{lcccc}
\hline \multirow{2}{*}{ Trait } & \multicolumn{2}{c}{ Fixed } & \multicolumn{2}{c}{ Random } \\
\cline { 2 - 5 } & HYS & Parity & Animal & PE \\
\hline NBA & $\times$ & $\times$ & $\S$ & $\S$ \\
LBWT & $\times$ & $\times$ & $\S$ & $\S$ \\
D21LS & $\times$ & $\times$ & $\S$ & $\S$ \\
D21LWT & $\times$ & $\times$ & $\S$ & $\S$ \\
& & & & \\
\hline
\end{tabular}

HYS: herd; year and season of farrowing; NBA: number born alive;

BWT: litter birth weight; D21LS: 21-day litter size; D21LWT: 21-day litter weight;

PE: permanent environmental effect of the sow; $\times$ : factor included and significant;

§: random effect fitted.

The genetic parameters were estimated using single-trait and two-trait repeatability animal models in ASREML (Gilmour et al., 2006). Variance and covariance estimates obtained from these analyses were used to estimate heritability estimates and genetic correlations between traits. Estimated breeding values based on animal solutions were averaged within birth years and used to plot genetic trends for the traits. The mixed model equation used, was as follows:

$\mathrm{y}=\mathrm{X} \beta+\mathrm{Zu}_{\mathrm{a}}+\mathrm{Wu}_{\mathrm{pe}}+\mathrm{e}$

where, $y$ is the vector of observations for sow productivity traits, $\beta$ is the vector of fixed effects, vectors of random effects consisted of random animal additive genetic $\left(\mathrm{u}_{\mathrm{a}}\right)$, permanent environmental $\left(\mathrm{u}_{\mathrm{pe}}\right)$ and residual (e) effects. Incidence matrices X, Z and W related fixed, direct genetic and permanent environmental effects, respectively to observations. Random effects were assumed to be sampled from a normal distribution with a mean of zero and variance covariance structure as shown below: 


$$
\begin{aligned}
{\left[\begin{array}{c}
\mathrm{y} \\
\mathrm{u}_{\mathrm{a}} \\
\mathrm{u}_{\mathrm{pe}} \\
\mathrm{e}
\end{array}\right] } & =\left[\begin{array}{c}
\mathrm{X} \beta \\
0 \\
0 \\
0
\end{array}\right] \\
\mathrm{V}\left[\begin{array}{c}
\mathrm{e} \\
\mathrm{u}_{\mathrm{a}} \\
\mathrm{u}_{\mathrm{pe}}
\end{array}\right] & =\left[\begin{array}{ccc}
\mathrm{I} \sigma_{\mathrm{e}}^{2} & 0 & 0 \\
0 & A \sigma_{\mathrm{a}}^{2} & 0 \\
0 & 0 & \mathrm{I} \sigma_{\mathrm{pe}}^{2}
\end{array}\right]
\end{aligned}
$$

where, $\mathrm{A}$ is the numerator relationship matrix, $\mathrm{I}$ is an identity matrix, $\sigma_{\mathrm{a}}^{2}$ is the direct genetic variance, $\sigma_{\text {pe }}^{2}$ is the permanent environmental variance and $\sigma^{2}$ is the residual variance. Heritability estimates were calculated by expressing the genetic variance as a proportion of the phenotypic variance. Repeatability was estimated as proportion of phenotypic variance due to the additive genetic variance plus the sow permanent environmental variance. Genetic and phenotypic variances and covariances were used in the calculation of genetic and phenotypic correlations.

\section{Results and Discussion}

Heritability estimates for the traits analysed are shown in Table 4. Heritability estimates for the variation in litter sizes and weights among sows ranged from $0.03 \pm 0.01$ for D21LS to $0.11 \pm 0.01$ for LBWT. The generally low heritability estimates for sow productivity traits are in agreement with most results in literature reported for other breeds (Noguera et al., 2002; Chimonyo et al., 2006; Roehe et al., 2009). The heritability estimate for NBA of $0.07 \pm 0.01$ is lower than those obtained by Noguera et al., (2002) for different parities, which averaged 0.10 . These heritability estimates suggested that slow genetic progress may be expected if genetic selection is applied on sows for these traits. The heritability estimates derived in the current study seemed to be decreasing from birth to 21 days. This may indicate the reduction of the sow's influence on the piglets' traits, being replaced by the piglets' own genetic potential as they grow. Furthermore, at the two ages (birth and 21 days), litter weight had a relatively higher heritability than litter size. Therefore, faster genetic progress may be expected in litter weight than litter size when genetic selection is applied.

Table 4 Estimates of genetic effects $\left(h^{2}\right)$, repeatability ${ }^{\circledR}$ and phenotypic variance $\left(\sigma_{P}^{2}\right)$

\begin{tabular}{lccc}
\hline & $\mathrm{h}^{2}$ & $\mathrm{r}$ & $\sigma_{\mathrm{P}}^{2}$ \\
\hline NBA & & & \\
LBWT & $0.07 \pm 0.01$ & $0.15 \pm 0.01$ & $5.39 \pm 0.05$ \\
D21LS & $0.11 \pm 0.01$ & $0.16 \pm 0.01$ & $11.22 \pm 0.11$ \\
D21LWT & $0.03 \pm 0.01$ & $0.11 \pm 0.01$ & $3.22 \pm 0.04$ \\
& $0.06 \pm 0.01$ & $0.12 \pm 0.01$ & $104.00 \pm 1.30$
\end{tabular}

NBA: sow number born alive; LBWT: sow litter birth weight; D21LS: sow 21-day litter size; D21LWT: sow 21-day litter weight.

Litter size has been recognized as the most important economic component of sow productivity (Estany et al., 2002). Litter size is a complex physiological trait affected by several component traits expressed sequentially, for example ovulation rate, fertilization, embryo survival and foetal survival (Leymaster et al., 1986). Thus, the low heritability for litter size may probably be due to it being a composite trait. Johnson et al. (1984) considered litter size a product of ovulation rate and embryonic survival, while Bennett \& Leymaster (1989) proposed a model in which litter size equals the minimum number of viable 
embryos or uterine capacity. This implies that mean litter size is a function of ovulation rate and uterine capacity, plus their interaction. Selection for litter size would therefore correspond to selection for the most limiting component. Also, there may be a negative correlation among some of the component traits, resulting in a low heritability. Some authors observed greater response in litter size after selecting for litter components (Neal \& Johnson, 1986; Neal et al., 1989; Bennett \& Leymaster, 1990). Haley \& Lee (1992) concluded that genetic variation in ovulation rate is largely responsible for the genetic variation in number of live pigs born, with no contribution from genetic variation in prenatal survival.

Litter birth weight reflects maternal genetic potential of the sow and accumulates genetic information per sow over its litter (Roehe, 1999). Chimonyo et al. (2006) attributed low heritabilities of individual birth weight and litter size to large differences in the genetic pool of breeding sows. In the current study, the low heritability of the sow productivity traits may be due to reduced genetic variation as a result of long-term selection for these traits.

Repeatability estimates for the sow productivity traits analysed are shown in Table 4. They ranged from $0.11 \pm 0.01$ for D21LS to $0.16 \pm 0.01$ for LBWT. As observed for the heritability estimates, litter weight traits had slightly higher repeatability estimates. These results also indicate that both genetic and permanent environmental effects of sow were higher for litter birth weight than for litter 21-day-weight. Fernandez et al. (2008) regarded mothering ability measured by D21LWT as a composite trait, combining litter size and average piglet weight at 21 days, which depend on the number of piglets born, as well as the piglets' pre-weaning survival and growth. These results indicate that the sow's performance is unlikely to be repeated during the production period. This may be because physiological development of reproductive organs differs with parity (Oh et al., 2006). Thus, milk production in gilts may be $20 \%$ lower than in multiparous sows, as a consequence of lower feed intake and additional requirements of energy for tissue growth (Walker \& Young, 1993). Therefore, sow performance during the first parity may not be used to predict its performance in future parities, particularly in D21LWT.

Table 5 contains genetic and phenotypic correlations among sow productivity traits. The genetic correlations ranged from $0.32 \pm 0.07$ between NBA and D21LWT to $0.88 \pm 0.04$ between NBA and D21LS. High positive genetic correlations of $0.78 \pm 0.05$ and $0.66 \pm 0.07$ for D21LS with D21LWT and with LBWT, respectively, were observed. The genetic correlation between LBWT and NBA is higher than the value of $0.263 \pm 0.033$ reported by Chimonyo et al. (2006) for indigenous Mukota pigs. Litter size and weight at 21 days had a genetic correlation lower than the literature mean value of 0.93 reported by Rothschild (1996). Selecting for NBA may also improve litter birth weight and 21-day litter size. Therefore, to improve the number of piglets weaned, selection should be based on NBA. Contrary to this, Damgaard et al. (2003) suggested that genetic selection for the sow's ability to give birth to an increased number of piglets born alive might impair their ability to give birth to homogeneous litters, which is vital for postnatal survival of piglets. This may underline the need to include postnatal survival in the analysis where cross-fostering is not practised, to evaluate the sow's ability to nurse a large number of piglets. The genetic correlation between LBWT and D21LWT $(0.55 \pm 0.05)$ may reflect the influence of birth weight on growth potential. Rehfeldt \& Kuhn (2006) observed the effect of birth weight on postnatal growth performance. Heavier piglets suckle

Table 5 Genetic (above the diagonal) and phenotypic (below the diagonal) correlations among sow productivity traits

\begin{tabular}{lcccc}
\hline & NBA & LBWT & D21LS & D21LWT \\
\hline NBA & & $0.64 \pm 0.03$ & $0.88 \pm 0.04$ & $0.32 \pm 0.07$ \\
LBWT & $0.75 \pm 0.01$ & & $0.66 \pm 0.07$ & $0.55 \pm 0.05$ \\
D21LS & $0.64 \pm 0.01$ & $0.57 \pm 0.01$ & & $0.78 \pm 0.05$ \\
D21LWT & $0.35 \pm 0.01$ & $0.44 \pm 0.01$ & $0.66 \pm 0.01$ &
\end{tabular}

NBA: litter size at birth; LBWT: litter weight at birth; D21LS: litter size at 21 days; D21LWT: litter weight at 21 days. 
more milk from the sow and gain more weight, hence are heavier at 21 days. Larger piglets may therefore stimulate or drain teats more effectively (English \& Morrison, 1984), which may direct a larger fraction of hormones and nutrients involved in milk production to their respective teats (Algers et al., 1991). Thus, if a litter has more heavy piglets at birth, these piglets will be heavier at 21 days; hence a higher litter weight. These results show that litter size can be improved by selecting for litter weight or vice versa. Litter size, however, has been reported to be negatively correlated to individual birth weight (Milligan et al., 2002; Damgaard et al., 2003). Therefore, the effort should be to improve both litter size and weight at the two ages by including these traits in the breeding objective.

The phenotypic correlations among sow productivity traits are shown Table 5 and ranged from $0.35 \pm$ 0.01 between NBA and D21LWT to $0.75 \pm 0.01$ between NBA and LBWT. These correlations indicate that sows producing larger heavier litters at birth may also wean larger litters. This may be attributed to the growth ability that heavier piglets have compared with lighter piglets, owing to their superior ability in draining teats more effectively (English \& Morrison, 1984; Algers et al., 1991). However, the phenotypic correlations for D21LWT with NBA and LBWT do not show a strong association between litter weaning weight and litter traits at birth. There may be need for supplementation of lactating sows to ensure heavier piglets are weaned.

The genetic and phenotypic trends shown in Figures 1 - 4 demonstrate discernible trends in sow productivity traits. The average increase in EBV for NBA from 1991 to 1999 was 0.02 piglets per year, which was followed by a decrease in the number of piglets born alive until 2006. On the other hand, the phenotypic performance increased at about 0.12 piglets per year from 1991 to 2002, after which it decreased. Litter birth weight EBVs increased at $0.03 \mathrm{~kg}$ per year from 1991 to 2002, and subsequently decreased at about $0.04 \mathrm{~kg}$ per year until 2006. The average phenotypic performance for LBWT increased from 1991 to 2003 at a rate of $0.17 \mathrm{~kg}$, and then decreased until 2006. A decrease in the average EBV for D21LS from 1992 to 1998 was observed, which was followed by inconsistent genetic trends. The phenotypic trend for D21LS increased slightly from 1990 to 1996, followed by a drop to 1997. Then there was a steady increase until 2006. The average EBV for D21LWT increased at $0.04 \mathrm{~kg}$ per year from 1991 to 2002, after which the trend was indiscernible. On the other hand, the average phenotypic performance for D21LWT increased at an average rate of $0.20 \mathrm{~kg}$ per year from 1991 to 2006. Neal \& Johnson (1986) and Haley \& Lee (1992) observed an increase in litter size after selecting for its components. Positive trends in number born alive and number weaned were also reported by Southwood \& Kennedy (1991) for Canadian Large White and Landrace pigs. They suggested that annual rates of genetic change of half a pig per litter are theoretically feasible using an index including relatives.

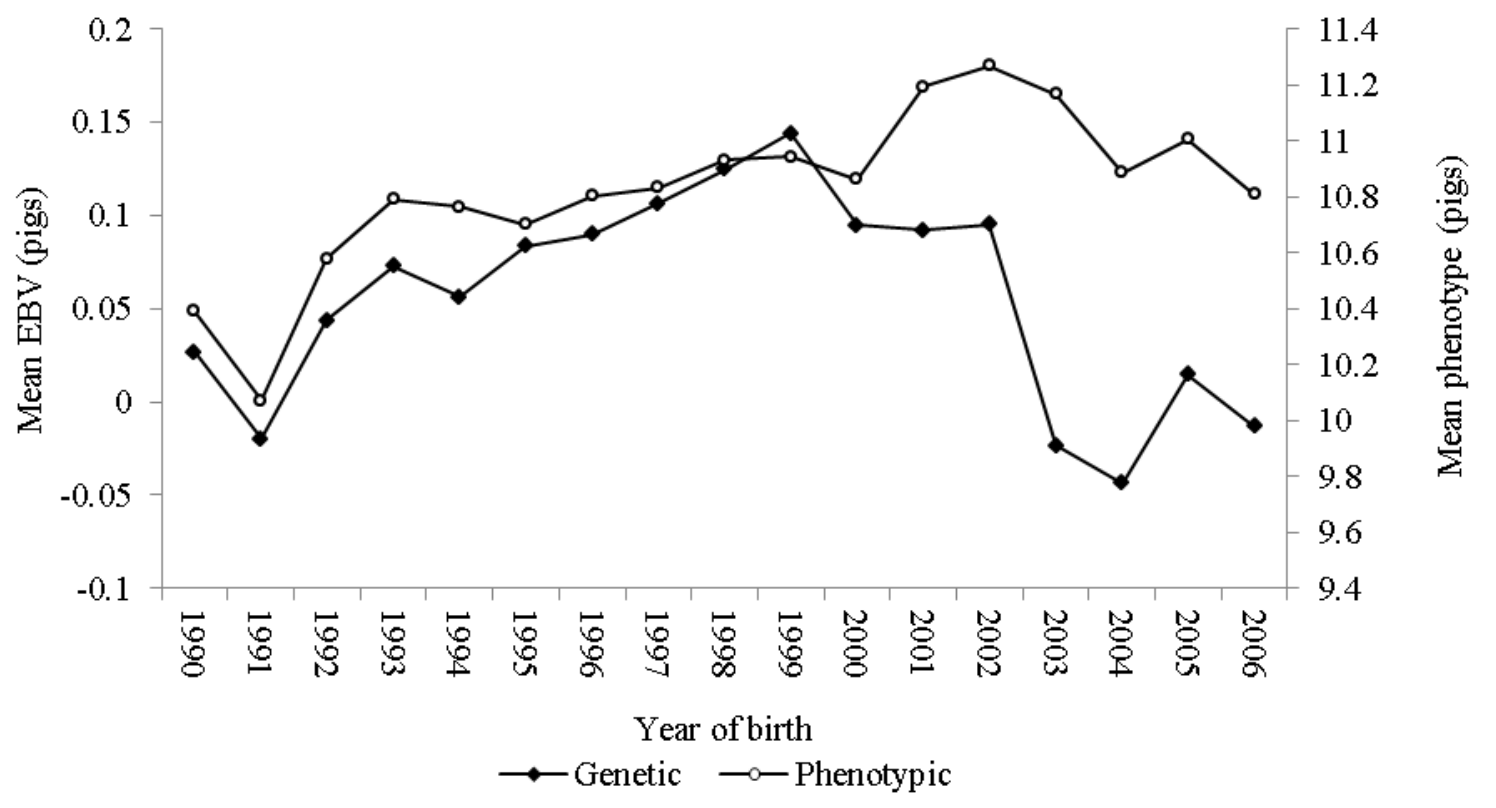

Figure 1 Genetic and phenotypic trends for litter size at birth. 
The improved phenotypic trends during some periods for sow productivity traits may be partly attributed to responses to direct and indirect genetic selection, as shown by the genetic trends that mirrored the phenotypic trends for litter traits at birth. This indicates that genetic selection is possible even in traits of low heritability, and this may interact positively with management to improve phenotypic performance. Generally, the genetic changes were below $10 \%$ of the phenotypic changes. This was expected as the heritability estimates of these traits were less than $10 \%$. These results underscore the importance of the role played by genetic selection in improving phenotypic performance. After 2000, it seems there were undesirable genetic and phenotypic changes, which may indicate a lack of consistent genetic selection being applied. Therefore, to improve sow productivity in this population, genetic selection practices should be purposeful.

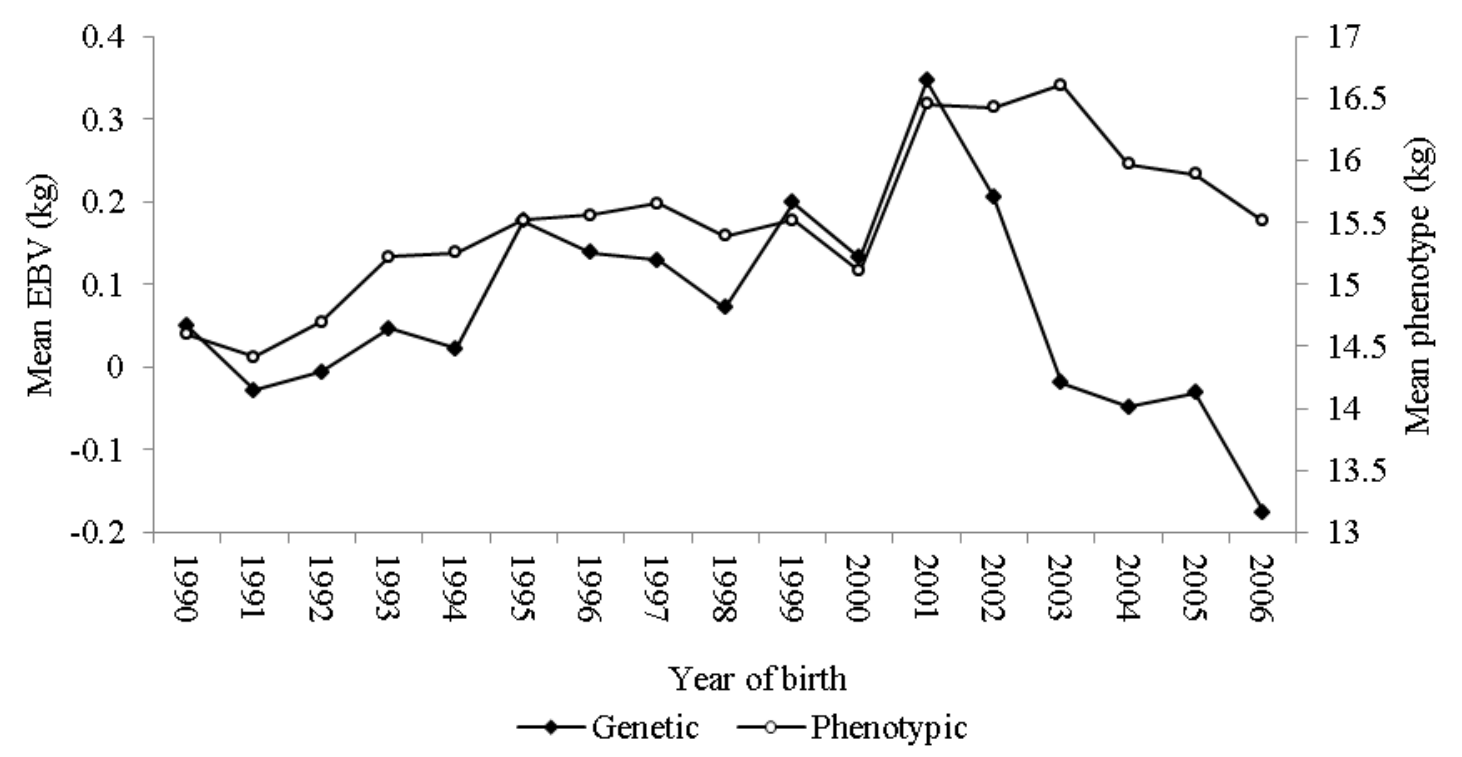

Figure 2 Genetic and phenotypic trends for litter weight at birth.

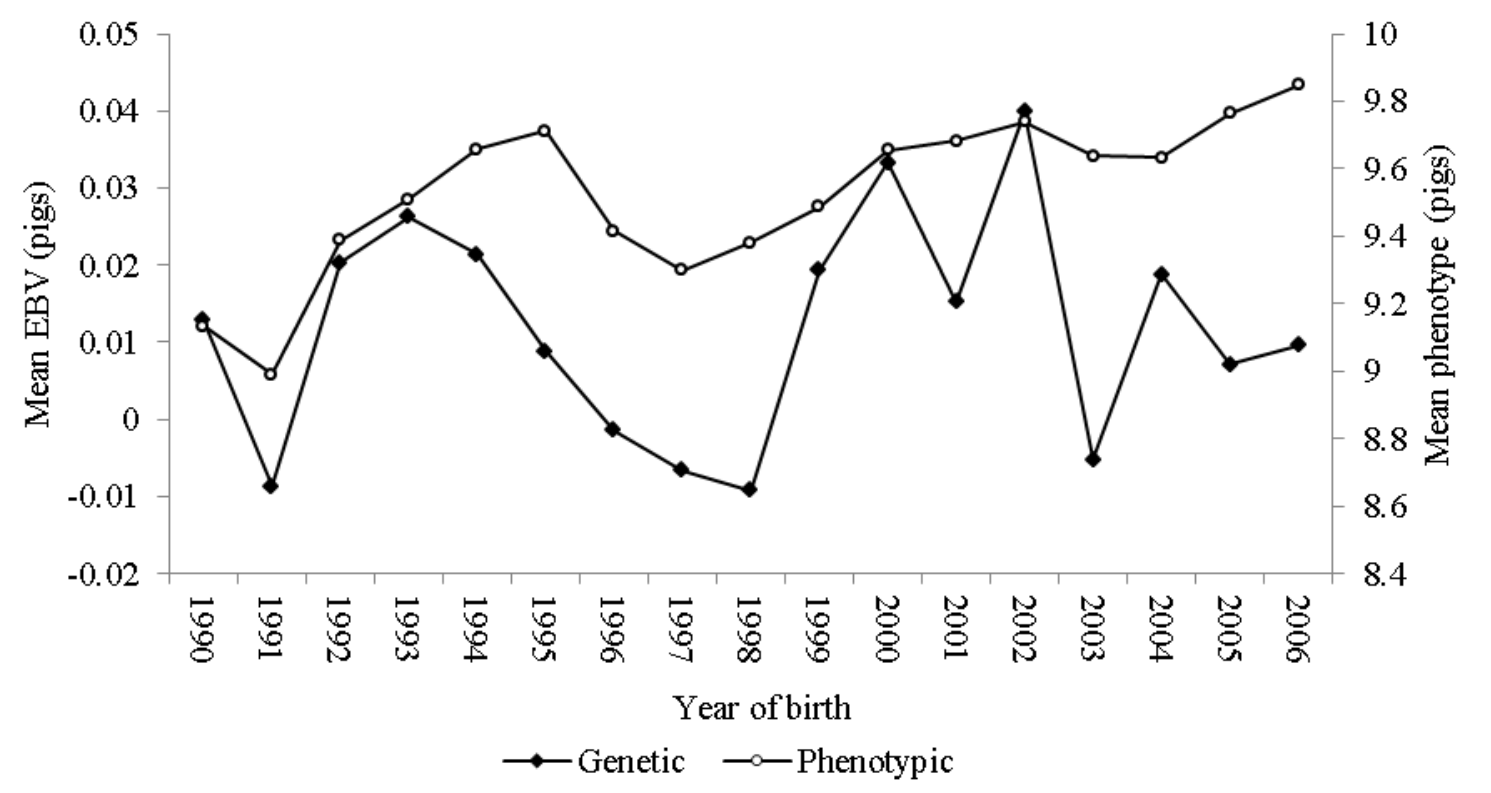

Figure 3 Genetic and phenotypic trends for litter size at 21 days. 


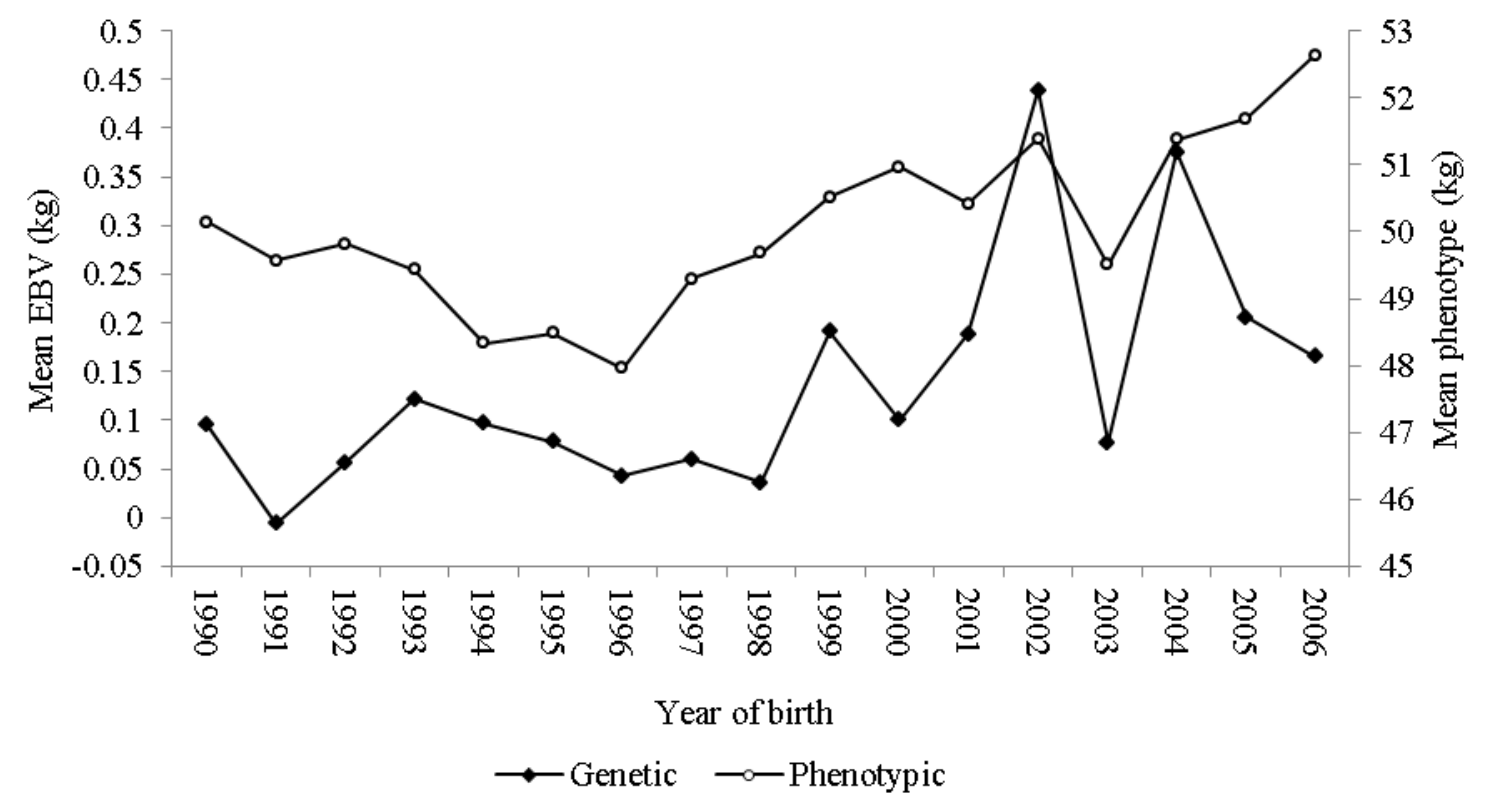

Figure 4 Genetic and phenotypic trends for litter weight at 21 days.

\section{Conclusion}

Sow productivity traits are generally of low heritability and repeatability in this population. Response to selection may therefore be slow, and previous sow performance may not reflect future performance for these traits adequately. Litter traits at birth in relative terms are more heritable and repeatable than litter traits at 21 days. Selection for litter size at birth may be expected to improve litter weight at birth and litter size at 21 days. Since sow productivity traits are lowly heritable, genetic selection may not always yield substantial additive gains. However, because of their economic importance an attempt should always be made to keep these traits at their optimum.

\section{Acknowledgement}

The data for this research was supplied by INTERGIS, hosted by the Agricultural Research Council Livestock Business Division, Irene, Pretoria. Special thanks to S.F. Voordewind, technical manager for Pig \& Poultry Recording and Improvement Scheme, AR-AP.

\section{References}

Algers, B., Madej, A., Rojanasthien, S. \& Uvnas-Moberg, K., 1991. Quantitative relationships between suckling-induced teat stimulation and the release of prolactin, gastrin, somatostatin, insulin, glucagon and vasoactive intestinal polypeptide in sows. Vet. Res. Commun. 15, 395-407.

Bennett, G.L. \& Leymaster, K.A., 1989. Integration of ovulation rate, potential embryonic viability and uterine capacity into a model of litter size in swine. J. Anim. Sci. 67, 1230-1241.

Bennett, G.L. \& Leymaster, K.A., 1990. Genetic implications of a simulation model of litter size in swine based on ovulation rate, potential embryonic viability and uterine capacity: II. Simulated selection. J. Anim. Sci. 68, 980-986.

Bereskin, B., 1984. A genetic analysis of sow productivity traits. J. Anim. Sci. 59, 1149-1163.

Chimonyo, M., Dzama, K. \& Bhebhe, E., 2006. Genetic determination of individual birth weight, litter weight and litter size in Mukota pigs. Livest. Sci. 105, 69-77.

Crump, R.E., Thompson, R. Haley, C.S. \& Mercer, J., 1997. Individual animal model estimates of genetic correlations between performance test and reproduction traits of Landrace pigs' performance tested in a commercial nucleus herd. Anim. Sci. 65, 291-298.

Damgaard, L.H., Rydhmer, L., Løvendahl, P. \& Grandinson, K., 2003. Genetic parameters for within-litter variation in piglet birth weight and change in within-litter variation during suckling. J. Anim. Sci. 81, 604-610. 
English, P.R. \& Morrison, V., 1984. Causes and prevention of piglet mortality. Pig NewsInfo. 5, 369-376.

Estany, J., Villalba, D., Tibau, J., Soler, J., Babot, D. \& Noguera, J.L., 2002. Correlated response to selection for litter size in pigs: I. Growth, fat deposition, and feeding behavior traits. J. Anim. Sci. 80, 2556-2565.

Fernández, A., Rodrigáñez, J., Zuzúarregui, J., Rodríguez, M.C. \& Silió, L., 2008. Genetic parameters for litter size and weight at different parities in Iberian pigs. Span. J. Agric. Res. 6, 98-106.

Ferraz, J.B. \& Johnson, R.K., 1993. Animal model estimation of genetic parameters and response to selection for litter size and weight, growth, and backfat in closed seedstock populations of large white and Landrace swine. J. Anim. Sci. 71, 850-858.

Gilmour, A.R., Gogel, B.J., Cullis, B.R. \& Thompson, R., 2006. ASReml User Guide Release 3.0. VSN International Ltd, Hemel Hempstead, HP1 1ES, UK.

Haley, C.S. \& Lee, G.J., 1992. Genetic factors contributing to variation in litter size in British Large White gilts. Livest. Prod. Sci. 30, 99-113.

Hanenberg, E.H.A.T., Knol, E.F. \& Merks, J.W.M., 2001. Estimates of genetic parameters for reproduction traits at different parities in Dutch Landrace pigs. Livest. Prod. Sci. 69, 179-186.

Irgang, R., Favero, J.A. \& Kennedy, B.W., 1994. Genetic parameters for litter size of different parities in Duroc, Landrace, and large white sows. J. Anim. Sci. 72, 2237-2246.

Johnson, R.K., Zimmerman, D.R. \& Kittok, R.J., 1984. Selection for components of reproduction in swine. Livest. Prod. Sci. 11, 541-549.

Kim, H.J., 2001. Genetic parameters for productive and reproductive traits of sows in multiplier farms. Ph.D. thesis, Georg-August- University of Gottingen, Gottingen, Germany.

Leymaster, K.A., Christenson, R.K. \& Young, L.D., 1986. A biological model to measure uterine potential for litter size in swine. Proc. $3^{\text {rd }}$ World Congr. Genet. Appl. Livest. Prod. XI, 209-216.

Milligan, B.N., Fraser, D. \& Kramer, D.L., 2002. Within-litter birth weight variation in the domestic pig and its relation to preweaning survival, weight gain and variation in weaning weights. Livest. Prod. Sci. 76, 181-191.

Neal, S.M. \& Johnson, R.K., 1986. Selection for components of litter size in swine: Genetic parameters and expected response. In: Proc. 3rd World Congr. Genet. Appl. Livest. Prod. Lincoln, NE. pp. 228-9233.

Neal, S.M., Johnson, R.K. \& Kittok, R.J., 1989. Index selection for components of litter size in swine: Response to five generations of selection. J. Anim. Sci. 67, 1933-1945.

Noguera, J.L., Varona, L. Babot, D. \& Estany, J., 2002. Multivariate analysis of litter size for multiple parities with production traits in pigs: I. Bayesian variance component estimation. J. Anim. Sci. 80, 2540-2547.

Oh, S.H., Lee, D.H. \& See, M.T., 2006. Estimation of genetic parameters for reproductive traits between first and later parities in pigs. Asian-Aust. J. Anim. Sci. 19, 7-12.

Rehfeldt, C. \& Kuhn, G., 2006. Consequences of birth weight for postnatal growth performance and carcass quality in pigs as related to myogenesis. J. Anim. Sci. 84, E113-E123.

Roehe, R., 1999. Genetic determination of individual birth weight and its association with sow productivity traits using Bayesian analyses. J. Anim. Sci. 77, 330-343.

Roehe, R. \& Kennedy, B.W., 1995. Estimation of genetic parameters for litter size in Canadian Yorkshire and Landrace swine with each parity of farrowing treated as a different trait. J. Anim. Sci. 73, 2959-2970.

Roehe, R., Shrestha, N.P., Mekkawya, W., Baxter, E.M., Knap, P.W., Smurthwaite, K.M., Jarvis, S., Lawrence, A.B. \& Edwards, S.A., 2009. Genetic analyses of piglet survival and individual birth weight on first generation data of a selection experiment for piglet survival under outdoor conditions. Livest. Sci. 121, 173-181.

Rothschild, M.F., 1996. Genetics and reproduction in the pig. Anim. Reprod. Sci. 42, 143-151.

SAS, 2003. SAS User's Guide. SAS Institute Inc., Cary, N.C., USA.

Southwood, O.I. \& Kennedy, B.W., 1991. Genetic and environmental trends for litter size in swine. J. Anim. Sci. 69, 3177-3182.

Walker, B. \& Young, B.A., 1993. Modeling milk yield, milk components and body composition changes in lactating sows. Livest. Prod. Sci. 30, 347-360. 